Research Paper

\title{
Online communication in a rehabilitation setting: Experiences of patients with chronic conditions using a web portal in Denmark
}

\author{
Jose Cerdan $^{\mathrm{a}, \mathrm{b}}$, Daniel Catalan-Matamoros ${ }^{\mathrm{c}, \mathrm{d}, *}$, Sarah Warny Berg ${ }^{\mathrm{e}}$ \\ a Physio- and Occupational Therapy Department, Hvidovre Hospital, Hvidovre, Denmark \\ ${ }^{\mathrm{b}}$ Respiratory Diseases and Allergology, Aarhus University Hospital, Aarhus, Denmark \\ ${ }^{c}$ Department of Journalism and Communication, University Carlos III of Madrid, Madrid, Spain \\ ${ }^{\mathrm{d}}$ Research group for Health Sciences CTS-451, University of Almeria, Almeria, Spain \\ e Optimov Tele-Rehabilitation, Copenhagen, Denmark
}

\section{A R T I C L E I N F O}

\section{Article history:}

Received 7 January 2017

Received in revised form 10 June 2017

Accepted 16 June 2017

\section{Keywords:}

Communication

Web portal

Patient's experiences

eHealth

Rehabilitation

\begin{abstract}
A B S T R A C T
Objective: To gain insight into the experiences of patients with long-term conditions enrolled in an online rehabilitation programme using a web portal.

Methods: Danish outpatients were recruited from a rehabilitation department and were granted access to a web portal which included an online rehabilitation programme with key information, clinical advice, and self-management activities. After two weeks, patients were invited to participate in focus groups. A topic guide was used to explore this new online rehabilitation programme in relation to participants' experiences.

Results: Fourteen participants, ranging from 42 to 72 years old, were allocated into three focus groups. Participants mainly reported negative experiences by the following four themes: 'patients' experiences', 'technical aspects', 'areas for improvement', and 'digitalization added value'.

Conclusion: Participants mainly reported negative experiences and suggested combining both face-toface consultations with online care by user-friendly web portals. This will ensure a positive contribution from digital communication tools to rehabilitation.

Practice implications: Patients' experiences should be considered in the design of web portals in rehabilitation which could help healthcare organizations when developing online rehabilitation programmes.
\end{abstract}

(C) 2017 Elsevier B.V. All rights reserved.

\section{Introduction}

Health information provided to patients is a key element in any care service. In Denmark, a survey conducted by the Unit of Patient Studies under the Ministry of Health and Prevention [1] has shown that patients are highly interested in information about their disease during the treatment and further healthcare interventions. The survey showed that most patients need written information, i.e., using online tools, together with the clinician's verbal information, due to the patients' limitations for understanding and retaining all information provided during face-to-face consultations [2].

Among the online communication tools that are spreading in healthcare, the web portal is becoming one of the most common

\footnotetext{
* Corresponding author at: Department of Journalism and Communication, University Carlos III of Madrid, Calle Madrid, 133, 28903 Getafe, Madrid, Spain. E-mail address: dacatala@hum.uc3m.es (D. Catalan-Matamoros).
}

ones [3]. It provides links to reliable sources of health information, appointments arrangement, care referrals management, medication renewals, etc. [4]. Web portals in healthcare settings deliver health services and education to persons with long-term conditions and their caregivers, and enable the patient's home to be the point of care. This growing industry empowers the patient and caregiver to gain self-care and coping skills [5], enhances clinical outcomes [6], and gets patients more involved in their own treatment [7]. However, although the majority of hospitals have built their own web portals, adoption rates are slow [8], and the portals have faced widespread resistance from patients [9]. According to previous research, these portals in healthcare settings need to make significant efforts to ensure privacy [10] and a patient-centred approach [11], as well as to increase quality information [12], improve clinician-patient communication $[13,14]$, provide feedback to users, and reduce difficulties for implementing web portal usage in daily life [15]. Furthermore, there is limited evidence evaluating the characteristics of patient portals [9]. 
Long-term clinical conditions are a growing public health challenge, and the current state of clinical consultation at healthcare facilities does not meet the needs of many of these patients [15]. Among these conditions, our study participants had been diagnosed with heart disease, lymphedema or chronic pulmonary obstructive disease. Long-term disease management programmes that use online communication tools offer an opportunity to shift the focus in healthcare away from hospital and towards the community. Moreover, the delivery of selfmanagement interventions via web portals provides the potential to reach a broader population of long-term ill patients for longer periods when compared with face-to-face interventions [16]. The potential of web portals to improve care during the entire continuum-including supportive care-has been recognized $[17,18]$. Additionally, patient-clinician communication is a critical domain of the quality of care [3], and web portals seem to improve the quality of care in the management of long-term diseases [9]. Nevertheless, the use of web portals in rehabilitation is a relatively new field [19], and further research is needed [17]. Since long-term disease management demands new approaches and there is a need to investigate rehabilitative patients' experiences with online programmes, we conducted a qualitative study aiming to gain insight into the experiences of patients with long-term conditions enrolled in an online rehabilitation programme using a web portal.

\section{Methods}

Within a rehabilitation department of a public hospital, we designed an online rehabilitation programme composed of a web portal with supportive information and programmes targeting patients with long-term conditions. The web portal was titled 'DPB-The Digital Patient Booklet', and it included information and exercise programmes, including clinical advice and self-management activities following the rehabilitation programme for each long-term condition (see Table 1). Further descriptions of the DPB web portal have been previously published $[20,21]$.

A systematic sample of outpatients in the rehabilitation department of a Danish public hospital was invited to participate in the study. A systematic sampling is a method of choosing a random sample from among a larger population. The inclusion criteria were: outpatients for at least one year, who had accessed the web portal during the last two weeks. Twenty-nine met the inclusion criteria, and all received an invitation letter before being included in the study. Each participant was granted access to the web portal module specific for his/her rehabilitation disease programme. Access and activities performed were tracked and recorded. All informants were informed about the study verbally and in writing, and signed a consent form to participate. The study design was approved by the Ethical and Research Committee of the Hvidovre Hospital, Denmark.

The 29 patients confirmed their enrolment, and they were randomly allocated into focus groups regardless of diagnosis and following a simple randomization system with dice [22]. A topic guide was built to explore participants' experiences, attitudes, and usages of the DPB web portal (see Table 2). Each focus group was conducted by one of three facilitators (SW, JC, and MP). The
Table 2

Topic guide used during the focus groups.

\begin{tabular}{l} 
Content \\
Amount of information \\
Language used (both in writing and verbally) \\
Ease in finding answers \\
Missing information \\
Video \\
3D exercise programme \\
Web portal vs face-to-face \\
Information received from each source \\
Duplications \\
Usage \\
When, how, what \\
Most useful sections \\
Patient's perception \\
Meaningfulness \\
Impact on treatment and rehabilitation \\
Motivation \\
Expectations \\
Need for technical advice \\
Problems for content search \\
Format \\
Motivation \\
Recommendation for future online rehabilitation programmes \\
\hline
\end{tabular}

sessions took place in a meeting room at the hospital, ensuring that participants could easily attend and feel relaxed. The sessions lasted approximately $120 \mathrm{~min}$ and were audio-recorded and transcribed verbatim. Sessions started with an introduction to the DPB web portal, followed by a 15 -min practical demonstration on how to access and use the different services available. After this, the facilitator continued with the focus group by following the topics guide as carefully planned while appearing to be spontaneous.

The Framework approach [23] was followed, whereby a coding frame was inductively constructed from the data [24]. The transcripts were read and coded independently by two of the researchers (authors SW and JC). All of the emerging themes and subthemes were directly supported by verbatim data from the focus groups. In order to ensure data integrity, in discussion with another member of the research team (author DC), disagreements about coding were discussed and resolved until 100 percent agreement was reached, and the coding frame, data analysis, and charts were validated. We did not set out with the overarching aim of generating theory from the findings.

\section{Results}

Data saturation was reached with three focus groups including 14 participants (see demographic characteristics in Table 3). From the invited outpatients, two patients declined to participate in the study due to unavailability. Each focus group comprised between four and five participants.

Participants provided very rich information, which has been synthesized into themes. Each theme is explored further, with examples of patients' quotes illustrating subthemes, which were created by group consensus identified after reading the transcripts. As a principle, a subtheme represents agreement by at least three

Table 1

Web portal content.

3-D exercise sets: developed in virtual reality, showed in a web game platform through a 3D human-like agent, providing visual explanation, real-time exploration, and music adjusted to the pace of the exercise performance.

E-learning packages: with video themes relevant for the patient groups, including topics such as 'Why is it important to train when you have this long-term disease?' and 'Tips on how to cope with your long-term diseases'. Followed by multiple-choice questionnaires that autoscore patient understanding on the topics explained in the videos.

Digital booklets: PDF files with booklets of exercises proposed for each long-term patient group, including pictures and text. 
Table 3

Demographic characteristics of the participants $(\mathrm{N}=14)$.

\begin{tabular}{ll}
\hline Age (years) & \\
Mean $( \pm \mathrm{SD})$ & $56.6( \pm 7.9)$ \\
Min - max & $42-72$ \\
& 7 \\
Female (n) & \\
Primary long-term condition (n) & 5 \\
Heart disease & 4 \\
Lymphedema & 5 \\
Chronic pulmonary obstructive disease & \\
\hline
\end{tabular}

participants. Single-participant quotes with no support from other participants were not considered. For all groups, the thematic content was found to be similar. While there were more detailed complaints by patients using the application for heart diagnosis, the perceived experiences were broadly shared across the focus groups. Therefore, our findings are pertinent to all focus groups. The following themes and subthemes emerged from the focus group discussions as the strongest patients' experiences about the use of the online rehabilitation-training programme (see Table 4).

\subsection{Patients' experiences}

The following seven subthemes were identified. In general, participants reported negative experiences when using the web portal. Quotes can be found online in Supplementary material 1.

- No commitment, no beginning, no end. Participants stressed that the reason why they are much more motivated to do exercises in a group with an instructor, rather than in their own home through the web portal, is first and foremost that with the portal there is no commitment. When they sign up with a group, the commitment and motivation increase. Second, when training at home, there is no fixed beginning of when they should start to exercise; even worse, there is no fixed ending. Thus, they tend to skip their training, which contributes to feelings of guilt regarding not doing enough about their disease.

- Personal contact feels safer. All patients would rather ask a clinician, such as a physician or a physiotherapist, to gather information about their long-term condition, than to search for the information on the Internet. This is why they consider the web portal as a tool for reassurance rather than a primary source of information. Some patients mentioned that it would motivate them if hospital staff would ask them about their experiences using the portal.

- Safer to train with a personal guide. Participants stressed that they would be anxious to train too hard at home, as they would be scared about possibly experiencing a strong physical reaction that requires professional assistance.

- My diagnosis, your responsibility. Many patients talked about their recovery as a very confusing process that included many misunderstandings. They have received contradictory messages from different clinicians, and they feel that they have not been well informed about the rehabilitation process. One participant pointed out that her lack of motivation to do all the prescribed exercise stemmed from feeling overwhelmed with so much new information since she received her diagnosis. She then explained how her everyday life had become more complicated, and that she is now doing everything at a lower pace.

- Check $\square$ Done! Many of the rehabilitation programme activities often remind patients of a kind of checklist process. To undertake exercise is perceived as a burden, something that they are happy about when it is over. Checking DPB seemed like a homework assignment for some participants.

- Too technical= too much effort. Getting access to the web portal requires a few downloads and some knowledge about web navigation. Some patients gave up, even before accessing the full web portal. As one patient said, 'The demands are too high now using the DPB'.

- Sick seeks 'non-sick'. Something that was mentioned is that sick people do not want to hang out with sick people; they just want to come back home and stay with family and friends. One participant admitted to some resistance in identifying himself as a sick person and meeting other people just because they share the same condition. A participant mentioned that the reason why he was not interested in sharing experiences about his diagnosis with other patients is that 'they basically don't care'.

\subsection{Technical aspects}

The following three subthemes were identified. Quotes can be found online in Supplementary material 2.

\section{Table 4}

Themes and subthemes of rehabilitation patients' experiences of a web portal.

\begin{tabular}{|c|c|}
\hline Themes & Subthemes \\
\hline 1. Patients' experiences & $\begin{array}{l}\text { No commitment, no beginning, no end } \\
\text { Personal contact feels more safe } \\
\text { V Safer to train with a personal guide } \\
\text { レ My diagnosis = your responsibility } \\
\text { レ Check } \square \text { Done! } \\
\text { レ Too technical = too much effort } \\
\text { レ Sicks seek 'non-sicks' }\end{array}$ \\
\hline 2. Technical aspects & $\begin{array}{l}\boldsymbol{V} \text { Getting access to the web portal } \\
\boldsymbol{レ} \text { Graphics and sound } \\
\boldsymbol{レ} \text { Communication }\end{array}$ \\
\hline 3. Areas for improvement & $\begin{array}{l}レ \text { Graphics and sound Less information, more video } \\
レ \text { Graphics and sound A step-by-step first aid guide } \\
\boldsymbol{レ} \text { Graphics and sound A medications guide } \\
\boldsymbol{レ} \text { Graphics and sound More concrete information }\end{array}$ \\
\hline 4. Digitalization added value & $\begin{array}{l}\boldsymbol{V} \text { Graphics and sound A step-by-step first aid guide DPB saves money } \\
\boldsymbol{レ} \text { Graphics and sound A step-by-step first aid guide A recap, not a source }\end{array}$ \\
\hline
\end{tabular}


- Getting access to web portal. Participants referred to some barriers when getting access to the web portal:

1. Website name: Some patients suggested creating a link to DPB on the website of Hvidovre Hospital, as they had difficulties remembering the specific website name patientpjecen.info. Furthermore, they stressed that a link on the hospital's main website would let more people receive information and increase the visibility of DPB.

2. Insufficient technical equipment: Several patients ascribed their access problems to the lack of minimum technical requirements.

3. Plug-in download requirement to view videos and 3D material: Many patients stopped their navigation within DPB when they encountered the requirement to download plug-ins for viewing videos and 3D material. They had heard that downloads may jeopardize their computer with viruses, and they also thought that it is too much effort to download something they are not familiar with.

4. Flyer codes: A few patients were confused about the flyer codes that should be used to access the DPB system. They pointed out that the paper on which the codes are written could get lost, and that the codes are sometimes unnecessary. These patients suggested that the code system should be replaced by a simple theme menu.

- Graphics and sound. Participants experienced annoyance with the graphics and sound to such an extent that it disturbed their experience with DPB. Participants stressed the following issues:

1. Images and videos: Some patients complained about the small size of images and poor-quality videos; these reduced their interest and motivation. The small images made many patients prefer watching the exercise DVD instead, since they can watch the DVD in larger formats on their wide-screen TV.

2. Sound: Some participants claimed that the sound was so poor (i.e., scratches or background noise) that they had to turn it off. This annoyed them greatly, especially as they spent considerable time trying to adjust the sound to a comfortable level. As many other patients did not complain about the sound quality, it is difficult to identify whether the sound problems are caused only by bad sound equipment in some personal computers. All patients with lymphedema stressed that the sound effect in one of the training videos was very discomforting, as it is very monotone-like and reminds them of a funeral parade (dungdungdung).

3. A real person, not an avatar: One focus group mentioned that the 3D training programme was well made and impressive to look at, but some others would rather look at a real person, not an avatar, while doing the exercises.

4. Lack of navigation in the videos: Many patients stressed that they became annoyed because they could not skip parts of the videos that they didn't want to watch. They wanted to be able to advance forwards and backwards and even step out of a video.

- Communication. Results show certain elements with regard to how the patients experienced communication and which areas should be improved:

1. Too many foreign words: Participants using the application for heart rehabiltiation were discouraged by the many foreign words within the text, mainly taken from the English language. They think that the information would be much easier to understand if it employed common language using their mother-tongue words (Danish).
2. Too little speech: Many patients suggested that a person's voice explaining the purpose and content of the exercises would provide them with a much more positive experience than just reading or viewing a video.

3. Bad speaker: Those participants with heart conditions were very annoyed by the perceived unprofessionalism of the narrator. One participant stressed that a professional vocalist should have been hired, since 'the person who gives the speech just reads the guidelines and keeps a monotone and boring tone'.

4. Better overview of videos: Many COPD patients mentioned that a video explaining how to use the positive expiratory pressure therapy flute (PEP-flute) would be very useful. However, a video on this topic was actually available in DPB; thus, patients need a better overview of the videos in order to ensure that they know how to search and find relevant information.

\subsection{Suggestions for improvement}

The following four subthemes were identified. Quotes can be found online in Supplementary material 3.

- Less information, more video: Many participants felt exhausted due to all the information they received about their diagnosis, and they felt much sicker when they read about their disease than when they didn't think about it. According to some participants, the videos decreased their stress and focus on the diagnosis. Patients highlighted that a step-by-step relapse management guide would be helpful for them in order to feel more secure and in control.

- Medication guide. The COPD participants asked for an overview of the effects and side effects of the different types of drugs consumed.

- More concrete information. The heart patients mentioned that they would prefer key useful advice for their everyday life.

\subsection{Digitalization added value}

Two subthemes were identified. Quotes can be found online in Supplementary material 4 .

- The web portal saves money. Some patients mentioned that they consider the portal as just a cost-reduction tool for the hospital. They had heard that all Danish citizens should be 'digitalized' by the year 2020, and they felt that the web portal could be linked to this process. However, these patients pointed out that this 'digitalization' is taking place years earlier and that there is still a huge proportion of the elderly population who have low technology literacy.

- A recap, not a source. Participants stressed that they prefer to get information about their diagnosis from face-to-face meetings with clinicians rather than looking at the web portal. Some participants mentioned that DPB works as some kind of dictionary, where, for example, they can look for information that they simply forgot.

\section{Discussion and conclusion}

\subsection{Discussion}

This qualitative study provides insights into the experiences of patients with long-term conditions using an online rehabilitationtraining programme through a web portal. The study mainly revealed negative experiences defined by the following four 
themes: 'patients' experiences', 'technical aspects', 'areas for improvement', and 'digitalization added value'. These cover a wide umbrella of areas that may be considered when implementing an online rehabilitation programme using a web portal. Before deepening the discussion, we provide a summary of the participants' concerns that should be considered when implementing a web portal in rehabilitation services:

1. Training at home with no direct face-to-face guiding was experienced as unsafe, low motivating and a burden.

2. A real person guiding the exercises in the web portal rather than an avatar was a suggestion for improvement, and watching videos was considered less stressful than reading written information.

3. Combining both face-to-face consultations and online care is recommended. The clinician should be the primary source of information, while the web portal should be used when some information is forgotten.

4. The web portal needs to be user-friendly (i.e. quality videos, images and professional vocalists) and easy to navigate (i.e. easy access and search tools). As few technical aspects and as little equipment as possible should be required, considering that elderly patients with long-term conditions have especially poor e-literacy.

5. More descriptions on exercise videos provided by a professional vocalist are suggested as a complement of the written materials. Key useful advice for everyday life is recommended.

In relation to the theme 'patient's experiences', the findings that participants felt low motivation and overwhelmed with so much new information are consistent with previous research. The amount of written information could be experienced as overwhelming in rehabilitation [21]; thus, patients often sort the information and select the most relevant pieces according to their needs and experiences [1]. Such patients have difficulties in assimilating the huge amount of information, since they are in a weak period of their life where everything is in a slower rhythm [25]. Indeed, in rehabilitation settings, especially during admission, patients may have been overwhelmed with the amount of content provided or may not have had enough background information to process the content. For rehabilitation patients, it has been suggested to go over the information slowly and clearly so they can understand it for themselves, rather than to depend on family members or caregivers alone [26].

It is well known that patients with long-term conditions feel more stress, panic, and depression [26,27]. In the case of rehabilitation programmes using the multimedia exercises of the DPB, patients feel that there is no fixed beginning or end of what they have to exercise every week. This produces a stressful feeling of confusion or guilt, as they tend to skip the training and do other things. To diminish such challenges, it seems to be useful to implement certain training programmes such as 'Check $\square$ Done!' to accomplish healthy milestones for the day. As a previous study revealed [29], patients need to understand that by following the schedule, they will maintain a healthy lifestyle and prevent exacerbations. Furthermore, the web portal may also be used as a tool to share the schedule with relatives or caregivers, as they also need to understand the rehabilitation programme [25].

With regard to the theme 'technical aspects', because many portals have been designed by physicians and IT specialists, and not by patients, redesign of the web portal might be needed to interest as many patients as possible and to address their specific wishes and needs [8]. In fact, participants' navigation of the web portal revealed key technical aspects that should be further considered towards the aim of creating a user-friendly web portal. Our study is consistent with others $[7,9]$, as user-friendliness is a concern for patients who are not familiar with advanced technology and therefore find it difficult to navigate a web portal. Technology should ensure security, well-being, and dignity for frail older people and should address their fears [30] about potential accidents that may occur during the rehabilitation activities. The technical areas focused on the content, accessibility, and use of the web portal. Participants demanded a more user-centred approach, which is considered relevant and effective for people with longterm conditions [31]. Moreover, users demanded an easier way to access and filter information in the web portal. It seems that receiving a flyer with the access passwords to be typed in from the main hospital website is not enough to ensure friendly access. Another study [32] found that these patients' web portals should stand alone, specifically for each patient group, as satellite websites from the main hospital website.

In relation to the theme 'areas for improvement', including chat and video-conference options might be positive additions, as well as incorporating a recorded human voice guiding the exercises, since the more real it is, the more motivation the users experience [33]. Another 'humanization' of the system might be the addition of sensors to the online exercise as motion-tracking systems to monitor and compare patients' performance with the 3D trainer. This could be expanded to include a real-time behavioural change of the 3D trainer, employing algorithms that evaluate whether patients are meeting their training goals and needs [34]. An example could be a COPD patient who is tracked by an oximeter that sends signals to the system that the patient is getting breathless; this then leads to a change in the behaviour of the 3D trainer to diminish the intensity of the exercise or to include a break during the exercise session. And even though the intention seems to be to make a rehabilitation programme as real as possible through the web portal, patients still expressed that it is important to have personal contact in order to feel their health care in 'good hands'. Agreeing with Kirkegaard et al., telemedicine solutions can't stand alone without the human presence of the healthcare provider who treats patients with long-term conditions [25]. Nevertheless, these online services might be a great complement, especially for the long-term sick population, as has been suggested by previous studies [34,35].

Finally, with regard to the 'digitalization added value' theme, it is well aligned with the general interest of national governments to digitize all services provided to their citizens. For example, the Danish government has fixed the deadline of the year 2020 to complete this digitalization process [37]. Thus, our study, following the current focus of public administrations, has explored how patients manage their disease with a digital tool, receiving rehabilitation services from just one place to be used 'anytime, anywhere'. Moreover, patients with long-term conditions often need counselling and support for long periods of time or the rest of their lives [21], so these online services could also support the sustainability of healthcare systems. In fact, the most important challenge that the public sector faces nowadays regarding patients with long-term conditions is to reduce their related costs of treatment, transport, home healthcare, and drugs [38]. The key point here is to explore whether digitalized self-management tools are the right approach to answer the current needs of society. In this regard, these systems should not be considered as the panacea to manage rehabilitation services, but should be planned together with other interventions such as face-to-face consultations during home rehabilitation [39], for example. This study did not analyse the cost-benefit result of self-management online tools; thus, we would recommend further research on this topic.

Our study has several limitations. First, it was conducted at one hospital. Consequently, our results may not be generalizable to other settings where patient portals are in use. Second, although a common focus-group topic guide was used for the three groups of 
patients, each addressed different issues. This could have led to questions being asked with different emphasis and answers recorded differently. Third, participants may have felt compelled to provide desirable responses during the focus groups because they were conducted in the same institution where they seek their care. Finally, the inclusion criteria were broad and there were no exclusion criteria. For example, variables such as age, comorbidities, functional level, and availability of technical devices at home (e.g., web camera or speakers) were not considered. However, the authors believe that this study brings innovative knowledge to the rehabilitation field, and the mentioned limitations should be considered in further research.

\subsection{Conclusion}

Participants mainly reported negative experiences and suggested combining both face-to-face consultations with online care by user-friendly web portals. This will ensure a positive contribution from digital communication tools to rehabilitation.

\subsection{Practice implications}

Patients' experiences should be considered in the design of web portals in rehabilitation which could help healthcare organizations when developing online rehabilitation programmes.

\section{Funding source}

This research did not receive any specific grant from funding agencies in the public, commercial, or not-for-profit sectors.

\section{Conflicts of interest}

None.

\section{Ethical issues}

Authors confirm all patient/personal identifiers have been removed or disguised so the patient/person(s) described are not identifiable and cannot be identified through the details of the story.

\section{Appendix A. Supplementary data}

Supplementary data associated with this article can be found, in the online version, at http://dx.doi.org/10.1016/j.pec.2017.06.023.

\section{References}

[1] Region Hovedstaden, Enheden for Brugerundersøgelser, Danske Regioner (forening), Danmark, Ministeriet for Sundhed og Forebyggelse, Den landsdækkende undersøgelse af patientoplevelser: spørgeskemaundersøgelse 70.742 indlagte og 164.860 ambulante patienter, Enheden for Brugerundersøgelser [The nationwide survey of patient experiences: survey 70,742 inpatients and 164,860 outpatients, Unit for Surveys], Region Hovedstaden, Frederiksberg, 2013.

[2] J. Díaz-Sáez, D. Catalán-Matamoros, M.M. Fernández-Martínez, G. GranadosGámez, La comunicación y la satisfacción de las primíparas en un servicio público de salud [Communication and satisfaction among primiparas in a public health service], Gac. Sanit. 25 (2011) 483-489, doi:http://dx.doi.org/ 10.1016/j.gaceta.2011.03.010.

[3] J.L. Lee, N.K. Choudhry, A.W. Wu, O.S. Matlin, T.A. Brennan, W.H. Shrank, Patient use of email, facebook, and physician websites to communicate with physicians: a national online survey of retail pharmacy users, J. Gen. Intern. Med. 31 (2016) 45-51, doi:http://dx.doi.org/10.1007/s11606-015-3374-7.

[4] S.N. Weingart, D. Rind, Z. Tofias, D.Z. Sands, Who uses the patient internet portal? The PatientSite experience, J. Am. Med. Inform. Assoc. 13 (2006) 91-95, doi:http://dx.doi.org/10.1197/jamia.M1833.

[5] L.E. Moody, E-health web portals: delivering holistic healthcare and making home the point of care, Holist. Nurs. Pract. 19 (2005) 156-160.
[6] C.Y. Osborn, L.S. Mayberry, S.A. Mulvaney, R. Hess, Patient web portals to improve diabetes outcomes: a systematic review, Curr. Diab. Rep. 10 (2010) 422-435, doi:http://dx.doi.org/10.1007/s11892-010-0151-1.

[7] M.S. Goel, T.L. Brown, A. Williams, A.J. Cooper, R. Hasnain-Wynia, D.W. Baker, Patient reported barriers to enrolling in a patient portal, J. Am. Med. Inform. Assoc. 18 (2011) i8-i12, doi:http://dx.doi.org/10.1136/amiajnl-2011-000473.

[8] M.C.M. Ronda, L.-T. Dijkhorst-Oei, G.E.H.M. Rutten, Patients' experiences with and attitudes towards a diabetes patient web portal, PLoS One 10 (2015) e0129403, doi:http://dx.doi.org/10.1371/journal.pone.0129403.

[9] C.S. Kruse, D.A. Argueta, L. Lopez, A. Nair, Patient and provider attitudes toward the use of patient portals for the management of chronic disease: a systematic review, J. Med. Internet Res. 17 (2015) e40, doi:http://dx.doi.org/10.2196/ jmir.3703.

[10] C. Pyper, J. Amery, M. Watson, C. Crook, Patients' experiences when accessing their on-line electronic patient records in primary care, Br. J. Gen. Pract. J. R. Coll. Gen. Pract 54 (2004) 38-43.

[11] C.Y. Osborn, L.S. Mayberry, S.A. Mulvaney, R. Hess, Patient web portals to improve diabetes outcomes: a systematic review, Curr. Diab. Rep. 10 (2010) 422-435, doi:http://dx.doi.org/10.1007/s11892-010-0151-1.

[12] N. Peña-Palenzuela, Calidad de las páginas web con información sobre el cáncer de mama: Una revisión bibliográfica [Quality of web pages with information about breast cancer: a literature review], Rev. Esp. Comun. Sal. 7 (2016) 104-112, doi:http://dx.doi.org/10.20318/recs.2016.3157.

[13] E. Huang, C.-C.A. Chang, Patient-oriented interactive E-health tools on U.S hospital Web sites, Health Mark. Q. 29 (2012) 329-345, doi:http://dx.doi.org/ 10.1080/07359683.2012.732871.

[14] R. Hess, C.L. Bryce, S. Paone, G. Fischer, K.M. McTigue, E. Olshansky, S. Zickmund, K. Fitzgerald, L. Siminerio, Exploring challenges and potentials of personal health records in diabetes self-management: implementation and initial assessment, Telemed. E-Health 13 (2007) 509-518, doi:http://dx.doi. org/10.1089/tmj.2006.0089.

[15] J.D. Ralston, D. Revere, L.S. Robins, H.I. Goldberg, Patients' experience with diabetes support programme based on an interactive electronic medical record: qualitative study, BMJ 328 (2004) 1159, doi:http://dx.doi.org/10.1136/ bmj.328.7449.1159.

[16] M. Solomon, S.L. Wagner, J. Goes, Effects of a Web-based intervention for adults with chronic conditions on patient activation: online randomized controlled trial, J. Med. Internet Res. 14 (2012) e32, doi:http://dx.doi.org/10.2196/jmir.1924

[17] M. Muñoz-Cruzado y Barba, A. López-Villegas, D. Catalán-Matamoros, Conclusiones y recomendaciones del I Congreso Internacional de Telemedicina e Investigaciñn Sanitaria [Conclusions and recommendations of the 1st international congress of telemedicine and health research], Rev. Esp. Comun. Sal. 7 (2016) 164-166, doi:http://dx.doi.org/10.20318/recs.2016.3442.

[18] J.G. Timmerman, T.M. Tönis, M.G.H. Dekker-van Weering, M.M. Stuiver, M.W.J. M. Wouters, W.H. van Harten, H.J. Hermens, M.M.R. Vollenbroek-Hutten, Cocreation of an ICT-supported cancer rehabilitation application for resected lung cancer survivors: design and evaluation, BMC Health Serv. Res. 16 (2016) 155, doi:http://dx.doi.org/10.1186/s12913-016-1385-7.

[19] M.M. Cruz-Cunha, I.M. Miranda, R. Martinho, R. Rijo (Eds.), Encyclopedia of EHealth and Telemedicine, IGI Global, 2016 http://services.igi-global.com/ resolvedoi/resolve.aspx?doi=10.4018/978-1-4666-9978-6. (Accessed 4 January 2017).

[20] J. Cerdán, D. Catalán-Matamoros, Innovación y retos en la comunicación online con los usuarios de un hospital [Innovation and challenges in online communication with hospital users], Estud. Comun. Salud, Sociedad Latina Comunicación Social, La Laguna (Tenerife), (2014), pp. 87-102 http://www. cuadernosartesanos.org/2014/cac63.pdf. (Accessed 14 December 2016).

[21] J. Christensen, R.-J. Nienhuis, S.-T. Lauridsen, J. Cerdan, H. Peoples, L. Laursen, 'Det er ligesom at have sin fysioterapeut I nærheden' Bruger undersøgelse af den Digitale Patientpjece ['It's like Having the Physiotherapist Nearby' User Survey of the Digital Patient Booklet], Hospital Hidovre, 2014, 2017 http:// patientpjecen.dk/wp-content/uploads/2013/12/Evaluering-Den-DigtalePatientpjece.pdf. (Accessed 28 November 2016).

[22] K.P. Suresh, An overview of randomization techniques: an unbiased assessment of outcome in clinical research, J. Hum. Reprod. Sci. 4 (2011) 811, doi:http://dx.doi.org/10.4103/0974-1208.82352.

[23] C. Salisbury, Postal survey of patients' satisfaction with a general practice out of hours cooperative, BMJ 314 (1997) 1594, doi:http://dx.doi.org/10.1136/ bmj.314.7094.1594.

[24] J.M. Corbin, A. Strauss, Grounded theory research: procedures, canons, and evaluative criteria, Qual. Sociol. 13 (1990) 3-21, doi:http://dx.doi.org/10.1007| BF00988593.

[25] L.P. Kirkegaard, A. Brandt, H. Timm, Palliativ indsats til KOL-patienter [Palliative care for COPD patients], Lungeforening Dan, (2013), pp. 76.

[26] S.W. Blackstone, D.R. Beukelman, K.M. Yorkston, Patient-Provider Communication: Roles for Speech-Language Pathologists and Other Health Care Professionals, Plural Publishing, San Diego, CA, 2015.

[27] F. Hasson, A. Spence, M. Waldron, G. Kernohan, D. McLaughlin, B. Watson, B. Cochrane, I can not get a breath: experiences of living with advanced chronic obstructive pulmonary disease, Int. J. Palliat. Nurs. 14 (2008) 526-531.

[29] I. De Godoy, Assessing the severity and prognosis of chronic obstructive pulmonary disease: is it still sufficient to measure FEV1 alone? J. Bras. Pneumol. Publicaçăo Of. Soc. Bras. Pneumol. E Tisilogia 33 (2007) xxiii-xxiiv.

[30] S. Sävenstedt, P.O. Sandman, K. Zingmark, The duality in using information and communication technology in elder care, J. Adv. Nurs. 56 (2006) 17-25, doi: http://dx.doi.org/10.1111/j.1365-2648.2006.03975.x. 
[31] B. Allen, Information Tasks Toward a User-Centered Approach to Information Systems, Academic Press, San Diego, 1996.

[32] J. Cerdán, D. Catalán, Calidad informativa y comunicación a través del portal web de an hospital [Information and Communication Quality Through a Hospital Web Portal], V Congr. Int. Lat. Comun. Soc. -V CILCS -Univ. Laguna, (2013) , pp. 1-16.

[33] J. Cerdán, M. Andonovska, P. Ravn, An experimental study in VR vs. conventional rehabilitation, Res. Thesis 8th Semester Medialogy Ålborg's Univ., (2008), pp. 76.

[34] B. Song, K.-H. Wolf, M. Gietzelt, O. Al Scharaa, U. Tegtbur, R. Haux, M. Marschollek, Decision support for teletraining of COPD patients, Methods Inf. Med. 49 (2010) 96-102, doi:http://dx.doi.org/10.3414/ME09-02-0005.

[35] M. Tousignant, N. Marquis, C. Pagé, N. Imukuze, A. Métivier, V.S. Mpt, A. Tremblay, In-home telerehabilitation for older persons with chronic obstructive pulmonary disease: a pilot study, Int. J. Telerehabil. 4 (2012) 7-14.
[37] Danske Regeringen, Den digitale vej til fremtidens velfærd [The Digital Path to Future Prosperity]. Den fællesoffentlige digitaliseringsstrategi 2011-2015, (2011).

[38] Kronisk obstruktiv lungesygdom [Chronic Obstructive Pulmonary Disease], Statens Institut for Folkesundhed, Copenhagen, Denmark, 2007 http://www. si-folkesundhed.dk/upload/kap_9_kronisk_obstruktiv_lungesygdom_kol.pdf. (Accessed 11 December 2016).

[39] R. López-Liria, D. Padilla Góngora, D. Catalán Matamoros, C. Arrebola López, P. Garrido Fernández, M.D.C. Martínez Cortés, F. Zurita Ortega, Analysis of the activity of mobile rehabilitation-physiotherapy units in primary care, Atencion Primaria Soc. Espanola Med. Fam. Comunitaria 42 (2010) 278-283, doi:http:// dx.doi.org/10.1016/j.aprim.2009.10.005. 